\title{
MicroRNA-451 protects against cardiomyocyte anoxia/reoxygenation injury by inhibiting high mobility group box 1 expression
}

\author{
JING XIE, XIAORONG HU, CHUNFENG YI, GANGYING HU, XIAOYA ZHOU and HONG JIANG \\ Department of Cardiology, Renmin Hospital of Wuhan University, \\ Cardiovascular Research Institute of Wuhan University, Wuhan, Hubei 430060, P.R. China
}

Received April 30, 2015; Accepted January 29, 2016

DOI: $10.3892 / \mathrm{mmr} .2016 .5192$

\begin{abstract}
High mobility group box 1 (HMGB1) protein serves an important role in myocardial ischemia/reperfusion (I/R) injury. MicroRNAs (miRNAs) are a group of small non-coding RNAs that regulate numerous signaling pathways involved in myocardial I/R injury. The present study aimed to investigate whether miR-451 protects against cardiomyocyte anoxia/reoxygenation (A/R) injury by attenuating HMGB1 expression. Neonatal rat ventricular cardiomyocytes were prepared and then subjected to $A / R$ injury. The effect of upregulation or downregulation of miR-451 on cell viability, apoptosis, superoxide dismutase (SOD) activity, and the expression of cleaved-caspase-3 and HMGB1 were measured accordingly. A luciferase assay was performed to further confirm whether miR-451 can directly recognize the 3'-untranslated region of HMGB1 in HEK293 cells. The expression of miR-451 was significantly decreased in the cardiomyocytes during $\mathrm{A} / \mathrm{R}$, and upregulation of miR-451 led to increased miR-451 expression $(\mathrm{P}<0.05)$. Upregulation of miR-451 significantly attenuated the loss of cardiomyocyte viability $(\mathrm{P}<0.05)$ and increased the intracellular levels of SOD during $\mathrm{A} / \mathrm{R}(\mathrm{P}<0.05)$. Furthermore, upregulation of miR-451 significantly decreased the apoptosis of cardiomyocytes during $\mathrm{A} / \mathrm{R}(\mathrm{P}<0.05)$. The HMGB1 mRNA and protein expression levels were significantly downregulated in the Ad-miR-451 group compared with those in the A/R group $(\mathrm{P}<0.05)$. In addition, upregulation of miR-451 reduced its translocation from the nucleus to the cytoplasm. The luciferase assay confirmed that HMGB1 mRNA is a direct target of
\end{abstract}

Correspondence to: Dr Hong Jiang or Dr Xiaorong $\mathrm{Hu}$, Department of Cardiology, Renmin Hospital of Wuhan University, Cardiovascular Research Institute of Wuhan University, 238 Jiefang Road, Wuchang, Wuhan, Hubei 430060, P.R. China E-mail: jianghwurm@163.com

E-mail: huxrwurm@163.com

Key words: microRNA-451, anoxia/reoxygenation, high mobility group box 1 protein, cardiomyocytes
miR-451 in cardiomyocytes. In conclusion, the present study suggested that upregulation of miR-451 could protect against A/R-induced cardiomyocyte injury by inhibiting HMGB1 expression.

\section{Introduction}

Myocardial infarction results in the ischemic death of cardiomyocytes, and is a major cause of mortality (1). Reperfusion therapy, the process of restoring the blood flow to the ischemic tissue, has been demonstrated to be an effective approach for preserving the region of the heart that was ischemic (2). However, reperfusion therapy may result in additional cellular injury. Myocardial ischemia and reperfusion (I/R) has been shown to induce local myocardial inflammation, the generation of reactive oxygen species (ROS) and apoptosis, which resulted in myocardial cell damage $(3,4)$. Previous studies revealed that high mobility group box 1 (HMGB1) protein, a novel pro-inflammatory factor that is passively released from necrotic and apoptotic cells, or secreted by activated immune cells, serves an important role in the pathogenesis of inflammatory diseases, including acute hepatic necrosis, atrial fibrillation, myocardial infarction and myocardial I/R injury (5-8). Furthermore, inhibition of HMGB1 has been demonstrated to attenuate myocardial I/R injury $(5,8)$.

MicroRNAs (miRNAs) are a group of small non-coding RNAs that negatively regulate gene expression via RNA-induced silencing complexes (RISC), leading to translational repression or mRNA degradation of their target genes (9-11). One miRNA could regulate the expression of hundreds of proteins. miRNAs regulate the expression of key proteins in different signaling pathways involved in physiological processes, such as myocardial I/R (12-14). Previous studies demonstrated that miR-1, miR-21, miR-133, miR-320, miR-29 and miR-451 act as regulators in the myocardial I/R process $(13,15-18)$. However, the association between miRNAs and HMGB1 remains unclear. Our previous study demonstrated an association between miR-451 and HMGB1 using the Target-Scan software (19). The present study investigated the hypothesis that miR-451 may induce cardioprotection in anoxia/reoxygenation (A/R) injury by attenuating HMGB1 expression in vitro. 


\section{Materials and methods}

Construction of adenoviral vectors. miR-451, antisense miR-451 and empty plasmid adenovirus (containing green fluorescent protein; GFP), termed Ad-miR-451, Ad-asmiR-451 and Ad-GFP, respectively, were generated by Shanghai Genechem (Shanghai Genechem Co., Ltd., Shanghai, China) by cloning miR-451 or antisense miR-451 primary DNA, or the empty plasmid in the reverse orientation relative to the CMV promoter. The recombinant viruses were then amplified in HEK293 cells (Shanghai Genechem Co., Ltd.) and purified using the Adeno-X Purification kit (Microbix Biosystems, Inc., Mississauga, ON, Canada) in order to reach the titer of $1,011 \mathrm{pfu} / \mathrm{ml}$.

Cell culture and treatment. The experimental protocol conformed to the Guideline for the Care and Use of Laboratory Animals (US National Institutes of Health publication, revised 2010) (20) and approved by the Institutional Animal Care and Use Committee of Wuhan University (Hubei, China). Sprague-Dawley rats (1-3 days old, $n=96)$ were purchased from the Center of Experimental Animal (Wuhan University, Hubei, China). Rats were kept under identical housing conditions (temperature: $18-22^{\circ} \mathrm{C}$, humidity: $50-60 \%$ ) with a $12 \mathrm{~h}$ light-dark cycle and access to water and food ad libitum. Rats were sacrificed under etherization and the hearts were removed under sterile conditions. Neonatal rat ventricular myocytes were prepared by enzymatic dissociation as previously described (21). Briefly, the hearts were harvested, finely minced with scissors, and then dissociated with $0.125 \%$ (w/v) trypsin (HyClone Laboratories; GE Healthcare Life Sciences, Logan, UT, USA) and $0.08 \%$ collagenase I (HyClone Laboratories; GE Healthcare Life Sciences) for $40 \mathrm{~min}$ at $37^{\circ} \mathrm{C}$. Cardiomyocytes were seeded at a density of $1 \times 10^{6}$ cells $/ \mathrm{ml}$ and cultured in Dulbecco's modified Eagle's medium nutrient mixture F-12 (DMEM/F12; HyClone Laboratories; GE Healthcare Life Sciences) supplemented with $15 \%$ fetal bovine serum (FBS; Shanghai Weike Biochemical Reagent Co., Ltd., Shanghai, China), $1 \%$ penicillin $(100 \mathrm{U} / \mathrm{ml}$; North China Pharmaceutical Huasheng Co., Ltd., Shijiazhuang, China) and $1 \%$ streptomycin $(100 \mu \mathrm{g} / \mathrm{ml}$; North China Pharmaceutical Huasheng Co., Ltd.) at $37^{\circ} \mathrm{C}$, with $5 \% \mathrm{CO}_{2}$ for 4 days. Cells were then randomly allocated into five groups and treated as follows: i) Control group, DMEM/F12 with $15 \% \mathrm{FBS}$; ii) A/R group, DMEM/F12 for $4 \mathrm{~h}$ anoxia followed by $2 \mathrm{~h}$ reoxygenation with DMEM/F12 with $15 \%$ FBS; and iii) A/R + Ad-GFP; iv) $\mathrm{A} / \mathrm{R}+\mathrm{Ad}-\mathrm{miR}-451$; and v) $\mathrm{A} / \mathrm{R}+\mathrm{Ad}-\mathrm{asmiR}-451$ groups were subjected to Ad-GFP, Ad-miR-451 and Ad-asmiR-451 (final MOI=100, infection time $=2 \mathrm{~h}$ ), respectively, $24 \mathrm{~h}$ prior to $\mathrm{A} / \mathrm{R}$ as described for group ii.

Flow cytometric analysis of transfection ratio and apoptosis rate. GFP expression was considered the marker of successful transfection of adenovirus, and the percentage of positive GFP fluorescence was considered the transfection ratio. Apoptosis was assessed by flow cytometric analysis of propidium iodide (PI) and Annexin V double staining (Multi Sciences (Lianke) Biotech Co., Ltd., Hangzhou, China). Briefly, cardiomyocytes were harvested following treatment, rinsed with phosphate-buffered saline (PBS) and suspended in $500 \mu \mathrm{l}$ binding buffer (Multi Sciences (Lianke) Biotech Co., Ltd.). Cells were then incubated with $5 \mu \mathrm{l}$ Annexin $\mathrm{V}$ and $5 \mu 1 \mathrm{PI}$, and the stained cells were analyzed using the BD LSRFORTESSA flow cytometer (BD Biosciences, Franklin Lakes, NJ, USA).

Reverse transcription-quantitative polymerase chain reaction (RT-qPCR) analysis. Total RNA was extracted from cells with TRIzol reagent according to the manufacturer's instructions (Roche Diagnostics, Indianapolis, IN, USA) and reverse transcribed to produce cDNA from total RNA with oligo-dT primers (Generay Biotech Co, Ltd., Shanghai, China). The cDNA synthesis reaction was performed using $2 \mu \mathrm{g}$ of total RNA and a Transcriptor First Strand cDNA Synthesis kit (Roche Diagnostics). The assessment of RNA integrity was conducted with an optical density (OD) measurement via a NanoDrop ND-1000 spectrophotometer (Thermo Fisher Scientific, Inc., Waltham, MA, USA) and an OD 260/280 ratio $>2$ was considered an acceptable indicator of subsequent cDNA synthesis. RT-qPCR reactions were performed in $20 \mu \mathrm{l}$ volumes using the LightCycler 480 SYBR Green I Master Mix (Roche Diagnostics) and the LightCycler 480 Real-time PCR system (Roche Diagnostics) according to the manufacturer's instructions. The reaction conditions were as follows: 1 cycle of $95^{\circ} \mathrm{C}$ for $10 \mathrm{~min}$, followed by 40 cycles of $95^{\circ} \mathrm{C}$ for $10 \mathrm{sec}$, $60^{\circ} \mathrm{C}$ for $10 \mathrm{sec}, 72^{\circ} \mathrm{C}$ for $20 \mathrm{sec}, 1$ cycle for $95^{\circ} \mathrm{C}$ for $5 \mathrm{sec}$ and $65^{\circ} \mathrm{C}$ for $1 \mathrm{~min}$. The samples were quantified by normalizing the gene expression levels of HMGB1 to that of the standard housekeeping $\beta$-actin gene, and the gene expression levels of miR-451 to that of U6 gene, and were expressed as relative mRNA levels compared with the internal controls using the $2^{-\Delta \Delta C q}$ normalization method (22).

Cell viability assay. Cell viability was determined using the cell counting kit (CCK)-8 assay (Dojindo Molecular Technologies, Inc., Tokyo, Japan) according to the manufacturer's instructions. Briefly, the cardiomyocytes were seeded and incubated for 4 days in 96-well plates at $1 \times 10^{5}$ cells/well prior to group separation as mentioned. The absorbance (optical density, OD) of each well was measured at $490 \mathrm{~nm}$ with an iMark microplate absorbance reader (Bio-Rad Laboratories, Hercules, CA, USA). The percentage cell viability $(\mathrm{CV})$ was calculated using the following formula: $\% \mathrm{CV}=($ mean OD of test wells) $/($ mean OD of control well) x 100 .

SOD activity assay. The oxidative stress injury was measured by the indexes of oxygen free radical in myocytes. SOD activity was measured using the SOD assay kit (Nanjing JianCheng Bioengineering Institute, Nanjing, China; cat. no. A001-1) according to the manufacturer's instructions.

Western blotting. Equal quantities of proteins $(15 \mu \mathrm{l})$ were separated on $10 \%$ SDS-polyacrylamide gels (run on $160 \mathrm{~V}$ for $70 \mathrm{~min}$ ) and then electro-transferred to a polyvinylidene difluoride membrane. The membranes were blocked with $5 \%$ non-fat milk for $1 \mathrm{~h}$ at room temperature, and rinsed twice for $2 \mathrm{~min}$ in Tris-buffered saline and Tween 20. Membranes were incubated with mouse monoclonal anti-HMGB1 (1:1,000; Sigma-Aldrich, St. Louis, MO, USA; cat. no. H9537), and rabbit polyclonal anti-caspase-3 and anti-GAPDH (1:1,000 and 
1:5,000; Cell Signaling Technology, Inc., Danvers, MA, USA; cat. nos. 9662 and 5174, respectively) primary antibodies as previously described (23), with an overnight incubation at $4^{\circ} \mathrm{C}$. The membranes were then incubated with the corresponding polyclonal goat anti-mouse or anti-rabbit horseradish peroxidase-conjugated secondary antibodies (Jackson ImmunoResearch Laboratories, Inc., West Grove, PA, USA; cat. nos. 115-035-003 and 111-035-003, respectively) for $1 \mathrm{~h}$ at room temperature. The proteins were visualized with the Pierce ECL kit (Thermo Fisher Scientific, Inc.; cat. no. NCI4106). The expression of proteins of interest were normalized to the GAPDH expression.

Luciferase assay. To confirm whether miR- 451 was able to directly recognize the 3'-untranslated region of HMGB1 and inhibit its expression, a luciferase assay was performed using the Dual-Luciferase Reporter Assay System (Promega Corporation, Madison, WI, USA) according to the manufacturer's instructions. Briefly, construct in which a fragment of the 3'-UTR of HMGB1 mRNA (containing either putative miR- 451 binding sequence or mutant putative miR-451 binding sequence) was cloned into a firefly luciferase reporter construct and transfected into HEK293 cells with an empty plasmid (pDNR-CMV) or a plasmid expressing miR-451 (pmiR-451). The luciferase activity was normalized to the Renilla luciferase signal in HEK293 cells. Results were determined as the firefly to Renilla luciferase activity ratio (Fluc/Rluc).

Statistical analysis. Data are expressed as the mean \pm standard deviation. Statistical analysis was performed using one-way analysis of variance followed by the Student-Newman-Keuls test. SPSS software, version 17.0 (SPSS, Inc., Chicago, IL, USA) was used for analysis. $\mathrm{P}<0.05$ was considered to indicate a statistically significant difference.

\section{Results}

Determining miR-451 expression in treated cardiomyocytes. The transfection ratio was determined by the GFP expression in the cells, and the ideal MOI was measured at 100 (transfection ratio, 87.6\%). Gain- and loss-of-function approaches were utilized to regulate miR-451 expression in the cultured cardiomyocytes. As demonstrated in Fig. 1A, miR-451 expression was significantly increased in the Ad-miR-451 group compared with the control group $(\mathrm{P}<0.05)$. In the Ad-asmiR-451 group, miR-451 expression was decreased compared with the Ad-miR-451 group (Fig. 1A). Treatment with $4 \mathrm{~h}$ anoxia followed by $2 \mathrm{~h}$ reoxygenation decreased the expression of miR-451 in the A/R alone group compared with the control group $(\mathrm{P}<0.05$; Fig. 1B). $A / R$ treatment significantly increased miR- 451 expression in the Ad-miR-451 group compared with the A/R alone group (P<0.05; Fig. 1B). miR-451 expression was markedly decreased in the Ad-asmiR-451 group compared with the Ad-miR-451 group (Fig. 1B). Furthermore, Ad-GFP alone had no significant effect on the expression of miR-451 in the A/R cardiomyocytes ( $\mathrm{P}>0.05$; Fig. 1).

Cell viability and SOD activity assays. As demonstrated in Fig. 2, the viability of cardiomyocytes was significantly decreased in the $\mathrm{A} / \mathrm{R}$ alone group compared with the control
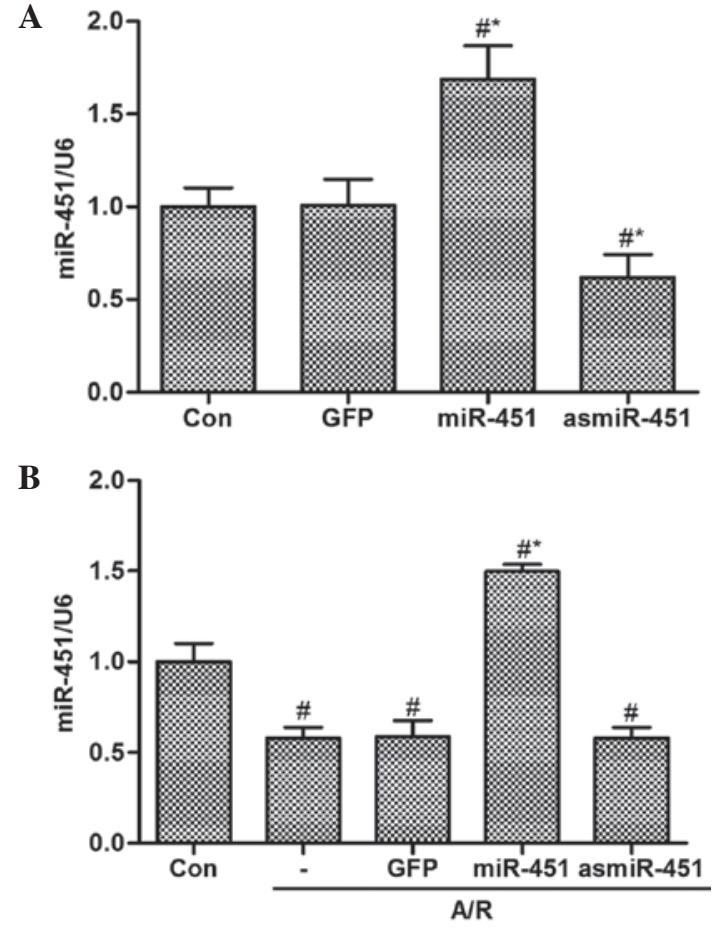

Figure 1. Determining miR-451 expression in treated cardiomyocytes by reverse transcription-quantitative polymerase chain reaction analysis. miR-451 expression was normalized to U6 expression. Relative miR-451 expression in (A) control, Ad-GFP, Ad-miR-451 and Ad-asmiR-451 groups, and $(\mathrm{B})$ control and $\mathrm{A} / \mathrm{R}$ treated groups. ${ }^{\text {}} \mathrm{P}<0.05$ vs. the control group and ${ }^{*} \mathrm{P}<0.05$ vs. the $\mathrm{A} / \mathrm{R}$ group. Con, control; GFP, green fluorescent protein; $\mathrm{A} / \mathrm{R}$, anoxia/reoxygenation; miR, microRNA.

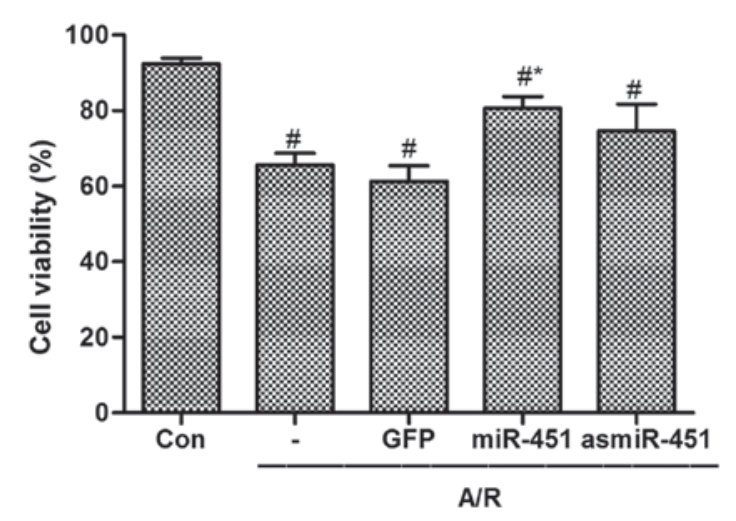

Figure 2. Effect of miR-451 on cell viability in control and A/R-treated cardiomyocytes. ${ }^{\#} \mathrm{P}<0.05$ vs. the control group and ${ }^{*} \mathrm{P}<0.05$ vs. the $\mathrm{A} / \mathrm{R}$ group. Con, control; GFP, green fluorescent protein; A/R, anoxia/reoxygenation; miR, microRNA.

group $(\mathrm{P}<0.05)$. Ad-miR-451 significantly attenuated cell viability during $A / R$ compared with the $A / R$ alone group $(\mathrm{P}<0.05$; Fig. 2). In addition, Ad-asmiR-451 and Ad-GFP alone had no significant effect on the cell viability compared with the A/R alone group ( $\mathrm{P}>0.05$; Fig. 2).

SOD activity was significantly decreased in the A/R alone group compared with the control group $(\mathrm{P}<0.05$; Fig. 3). Ad-miR-451 significantly inhibited the increase of SOD during $A / R$ compared with the control group $(\mathrm{P}<0.05$; Fig. 3), and significantly increased SOD activity compared with the A/R group ( $\mathrm{P}<0.05$; Fig. 3$)$. Ad-asmiR-451 could 


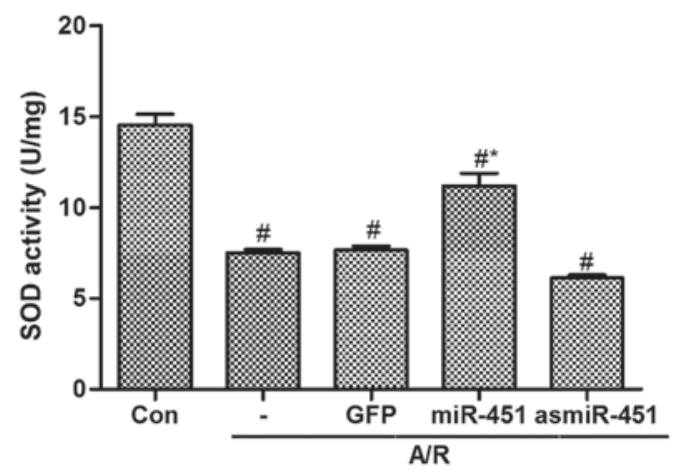

Figure 3. Effect of miR-451 on the SOD activity in control and A/R treated cardiomyocytes. ${ }^{\#} \mathrm{P}<0.05$ vs. the control group and " $\mathrm{P}<0.05 \mathrm{vs}$. the $\mathrm{A} / \mathrm{R}$ group. SOD, superoxide dismutase; con, control; GFP, green fluorescent protein; A/R, anoxia/reoxygenation; miR, microRNA.

A

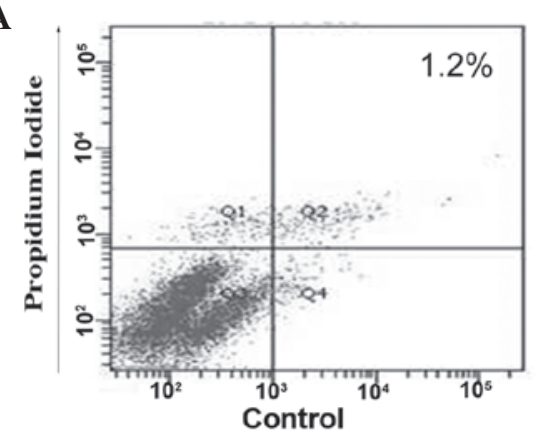

D

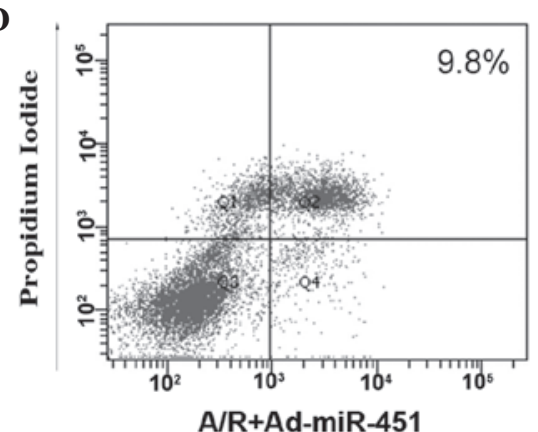

B

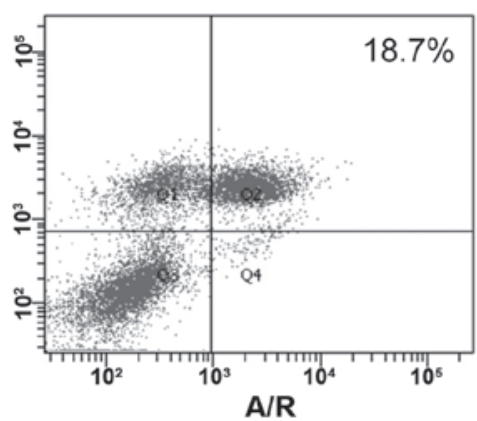

$\mathbf{E}$

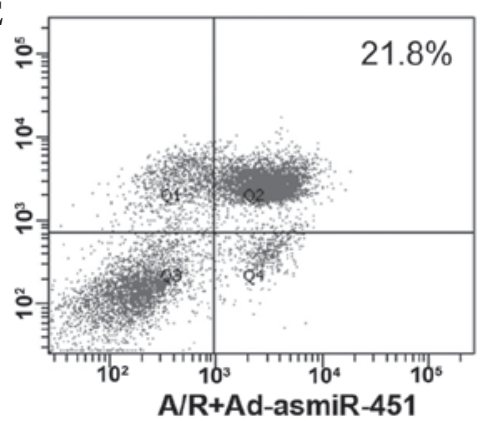

C
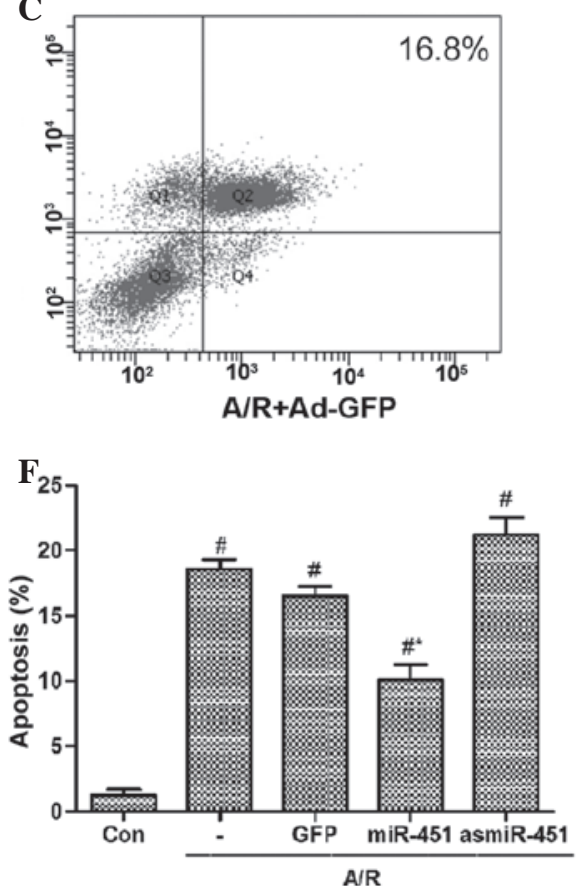

Figure 4. Effect of miR-451 on cell apoptosis in control and A/R treated cardiomyocytes. Cells were stained with Annexin V and propidium iodide to analyze apoptotic cell rate using flow cytometry in the (A) control, (B) A/R, (C) A/R + Ad-GFP, (D) A/R + Ad-miR-451 and (E) A/R + Ad-asmiR-451 groups. (F) Quantification of apoptosis in the treated groups. Q1 indicates the necrotic cells due to mechanical damage, Q2 indicates late apoptotic cells, Q3 indicates live cells and Q4 indicates early apoptotic cells. " $\mathrm{P}<0.05$ vs. the control group and ${ }^{*} \mathrm{P}<0.05$ vs. the A/R group. Con, control; A/R, anoxia/reoxygenation; GFP, green fluorescent protein; miR, microRNA.

slightly aggravate the increase of SOD during A/R compare with the Ad-miR-451 group ( $>>0.05$; Fig. 3). Ad-GFP alone had no significant effect on SOD activity during $A / R(P>0.05$; Fig. 3).

Effect of miR-451 on A/R-induced cardiomyocyte apoptosis. The apoptosis rate of cardiomyocytes was significantly increased in the $\mathrm{A} / \mathrm{R}$ alone group compared with control group $(\mathrm{P}<0.05$; Fig. 4). Ad-miR-451 significantly suppressed the apoptosis of cardiomyocytes during A/R compared with the A/R alone group $(\mathrm{P}<0.05$; Fig. 4). Ad-asmiR-451 and Ad-GFP alone had no significant effect on the apoptosis of cardiomyocytes during A/R (P>0.05; Fig. 4).

Relative HMGB1 expression in cardiomyocytes. RT-qPCR revealed that HMGB1 mRNA expression was significantly decreased in the Ad-miR-451 group during A/R compared with the $A / R$ alone group $(\mathrm{P}<0.05$; Fig. 5). The mRNA expression of HMGB1 was not significantly changed in the Ad-asmiR-451 group compared with that in the $A / R$ group ( $\mathrm{P}>0.05$; Fig. 5).

HMGB1 relative protein expression was significantly increased during $\mathrm{A} / \mathrm{R}$ compared with the control group $(\mathrm{P}<0.05$; Fig. 6A and $\mathrm{B})$. In the Ad-miR-451 group, HMGB1 relative protein expression was significantly decreased compared with the A/R alone group ( $\mathrm{P}<0.05$; Fig. 6A and $\mathrm{B})$. The HMGB1 relative protein expression was not significantly changed in the Ad-asmiR-451 group compared with the A/R alone group ( $\mathrm{P}>0.05$; Fig. 6A and $\mathrm{B})$.

Cleaved-caspase-3 relative protein expression in cardiomyocytes. The cleaved caspase-3 relative expression was 


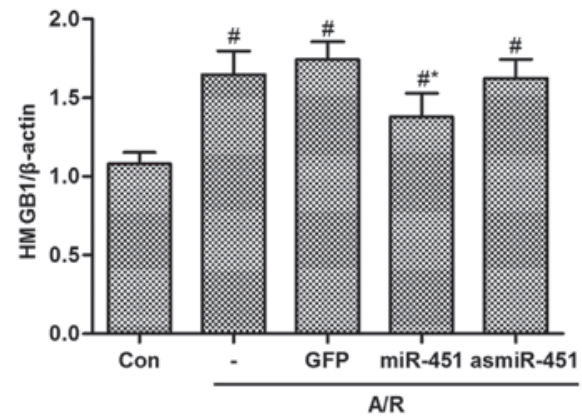

Figure 5. Effect of miR-451 on HMGB1 relative mRNA expression in cardiomyocytes by reverse transcription-quantitative polymerase chain reaction analysis. HMGB1 expression was normalized to $\beta$-actin expression. Relative HMGB1 expression in control and $\mathrm{A} / \mathrm{R}$-treated groups. ${ }^{\#} \mathrm{P}<0.05$ vs. the control group and ${ }^{*} \mathrm{P}<0.05$ vs. the A/R group. HMGB1, high mobility group box 1; con, control; GFP, green fluorescent protein; A/R, anoxia/reoxygenation; miR, microRNA.
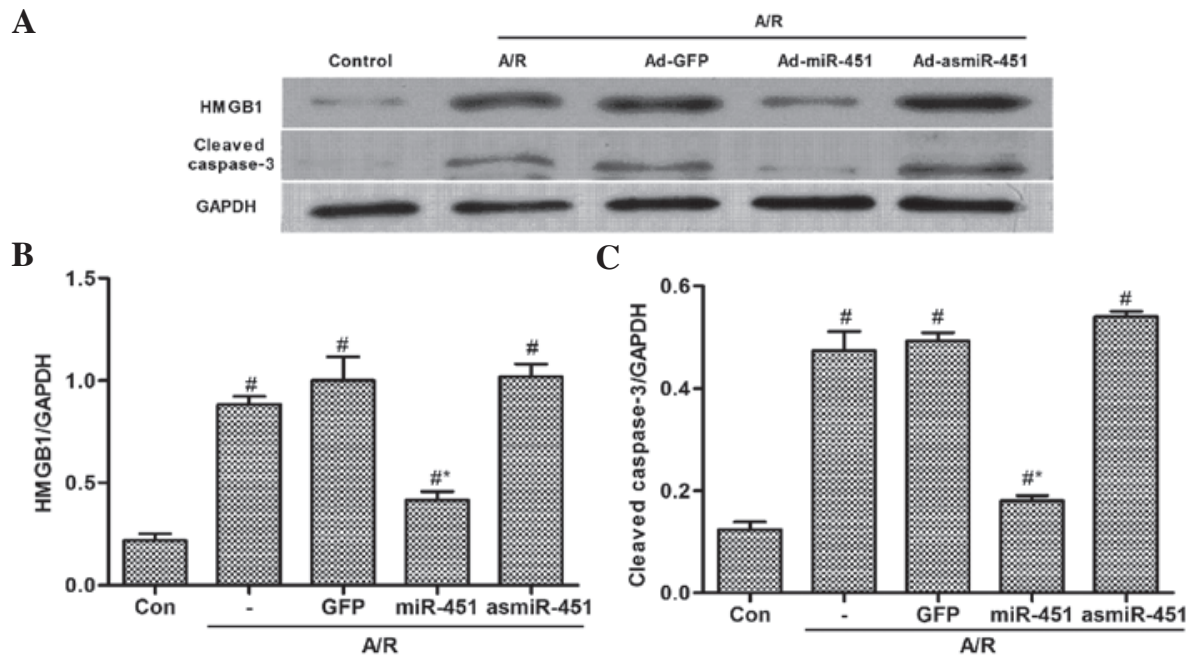

Figure 6. Effect of miR-451 on HMGB1 and cleaved-caspase-3 relative protein expression in cardiomyocytes. (A) Western blot analysis, levels of HMGB1 and cleaved-caspase-3 expression were normalized to GAPDH expression. Quantification of (B) HMGB1 expression and (C) cleaved-caspase-3 in control and $\mathrm{A} / \mathrm{R}$ treated groups. ${ }^{~} \mathrm{P}<0.05$ vs. the control group and ${ }^{~} \mathrm{P}<0.05$ vs. the $\mathrm{A} / \mathrm{R}$ group. HMGB1, high mobility group box $1 ; \mathrm{A} / \mathrm{R}$, anoxia/reoxygenation; GFP, green fluorescent protein; con, control; miR, microRNA; GAPDH, glyceraldehyde 3-phosphate dehydrogenase.

significantly increased during $\mathrm{A} / \mathrm{R}$ compared with the control group $(\mathrm{P}<0.05$; Fig. $6 \mathrm{~A}$ and $\mathrm{C})$, and significantly decreased in the Ad-miR-451 group compared with the $\mathrm{A} / \mathrm{R}$ alone group $(\mathrm{P}<0.05$; Fig. 6A and C). In the Ad-asmiR-451 no significant change was observed in the protein levels of cleaved caspase-3 compared with that in the A/R alone group ( $\mathrm{P}>0.05 ;$ Fig. $6 \mathrm{~A}$ and $\mathrm{C})$.

$H M G B 1 \mathrm{mRNA}$ as a target of miR-451 in cardiomyocytes. The luciferase assay was performed to verify HMGB1 as one of the target genes of miR-451 in cardiomyocytes. A construct in which a fragment of the 3'-UTR of HMGB1 mRNA containing the putative or mutant-putative miR-451 binding sequence, was cloned into a firefly luciferase reporter and cotransfected into HEK293 cells with the plasmid expressing miR-451. The luciferase assay was conducted to further confirm that HMGB1 was a direct target of miR-451 in the HEK-293T cells. The results demonstrated that miR-451 transfection significantly inhibited the luciferase activity of wild type HMGB1 3' UTR and not the mutant HMGB1 3' UTR with the mutant binding site of miR-451 (Fig. 7). These results demonstrated that HMGB1 is a direct target of miR-451 in HEK-293T. The results suggested that miR-451 binds to HMGB1 mRNA directly and inhibits its expression.

\section{Discussion}

Previous studies have demonstrated that miR-451 serves an important role in the cell death/survival process in the pathogenesis of breast cancer, leukemia and oxidant stress (24-26). The present study demonstrated that miR-451 inhibited cell apoptosis and oxidative stress injury, and increased cell viability during A/R injury. Ren et al (13) indicated that the expression levels of miR-451 were significantly decreased in rat I/R models. Previous studies have demonstrated that ectopic expression of miR-144 and miR-451 individually augmented cardiomyocyte survival, that was further improved by overexpression of miR-144/451 in response to simulated I/R, compared with the control group. The results from these studies indicated that the miR-144/451 cluster protected against simulated I/R-induced cardiomyocyte death via targeting the CUG triplet repeat-binding protein 2-cyclooxygenase-2 pathway. These studies suggested that overexpression of miR-451 may protect against the simulated $\mathrm{I} / \mathrm{R}$ injury in cardiomyocytes $(18,27)$. Ischemic preconditioning is a classic and effective method for protecting against $I / R$ injury. However, Wang et al (27) demonstrated that it fails to protect against I/R injury in miR-144/451-knockout mice. 
A

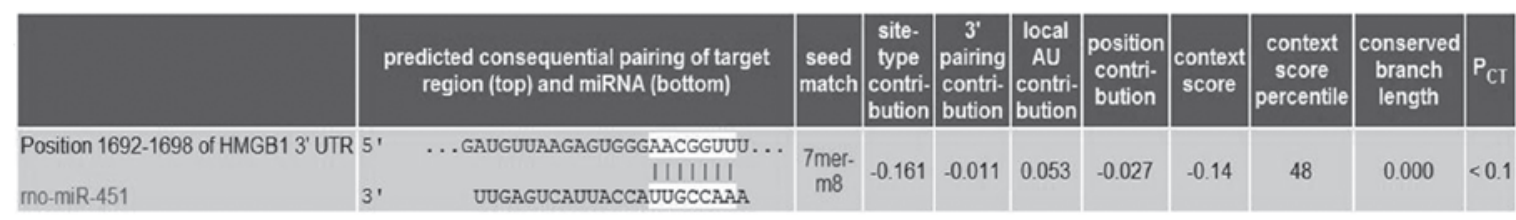

B

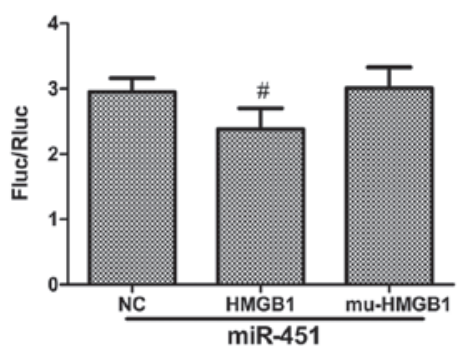

Figure 7. Association of miR-451 and HMGB1. (A) Computationally predicted interactions between miR-451 and the 3'-UTR HMGB1, as identified by the TargetScan software. (B) miR-451 targets and inhibits HMGB1 in HEK293 cells. ${ }^{\text {P }}<0.05$ vs. the miR-451 + NC group. HMGB1, high mobility group box 1; UTR, untranslated region; fluc/rluc, firefly to Renilla luciferase activity ratio; NC, normal control; mu-HMGB1, mutant HMGB1; miR, microRNA.

HMGB1 serves an important role in the process of $\mathrm{I} / \mathrm{R}$ injury in liver, brain, lung and heart tissues (28-30). Once released from necrotic or activated immune cells, HMGB1 triggers the downstream inflammatory process and promotes the release of pro-inflammatory cytokines, such as tumor necrosis factor- $\alpha$ (TNF- $\alpha$ ), interleukin-6 (IL-6) and C-reactive protein (CRP), leading to cell apoptosis (28,31-33). In addition, Andrassy et al (5) demonstrated that HMGB1 functions as an early mediator of inflammation and cell injury during myocardial I/R, whereas HMGB1 A box peptide (a specific HMGB1 antagonist) reduces myocardial $\mathrm{I} / \mathrm{R}$ injury and inhibits the release of TNF- $\alpha$ and IL-6. These results indicated that inhibition of HMGB1 may have a significant impact on improving cardiomyocyte survival during myocardial I/R injury. It has been identified by computational analysis that HMGB1 is a potential target gene of miR-451 (19). HMGB1 mRNA and protein levels were significantly changed following upregulation of miR-451 expression. The consistency between mRNA and protein levels suggested that miR-451 may downregulate HMGB1 expression by degrading its mRNA and obstructing the translation process. The binding site between miR-451 and HMGB1 was confirmed using a construct with a fragment of the 3'-UTR of HMGB1 mRNA containing the putative miR-451 binding sequence. The results of the present study demonstrated that upregulation of miR-451 may protect against A/R-induced injury in cardiomyocytes via inhibition of HMGB1.

In conclusion, the present study suggested that upregulation of miR-451 could protect against A/R-induced cardiomyocyte injury by inhibiting HMGB1 expression. Potential targets regulated by miR-451 have been predicted by TargetScan software (new 19), however, additional target validation experiments are required. In addition, further research is required to determine the molecular mechanisms of miR-451-regulated HMGB1 expression in cardiomyocytes.

\section{Acknowledgements}

The present study was partially supported by the National Natural Science foundation of China (grant nos. 81100146 and 81370308), the Natural Science foundation of Hubei (grant no. 2013CFB250), the Specialized Research Fund for the Doctoral Program of Higher Education of China (grant no. 20110141120060) and the Fundamental Research Funds of Wuhan City (grant no. 2013070104010044).

\section{References}

1. Guilbert JJ: The world health report 2002-reducing risks, promoting healthy life. Educ Health (Abingdon) 16: 230, 2003.

2. Becker LC and Ambrosio G: Myocardial consequences of reperfusion. Prog Cardiovasc Dis 30: 23-44, 1987.

3. Gottlieb RA and Engler RL: Apoptosis in myocardial ischemia-reperfusion. Ann N Y Acad Sci 874: 412-426, 1999

4. Zweier JL and Talukder MA: The role of oxidants and free radicals in reperfusion injury. Cardiovasc Res 70: 181-190, 2006.

5. Andrassy M, Volz HC, Igwe JC, Funke B, Eichberger SN, Kaya Z, Buss S, Autschbach F, Pleger ST, Lukic IK, et al: High-mobility Group box-1 in ischemia-reperfusion injury of the heart. Circulation 117: 3216-3226, 2008.

6. Hashimoto T, Ishii J, Kitagawa F, Yamada S, Hattori K, Okumura M, Naruse H, Motoyama S, Matsui S, Tanaka I, et al: Circulating high-mobility Group box 1 and cardiovascular mortality in unstable angina and non-ST-segment elevation myocardial infarction. Atherosclerosis 221: 490-495, 2012.

7. Hu XR, Wang XH, Liu HF, Zhou WJ and Jiang H: High mobility Group box 1 protein: Possible pathogenic link to atrial fibrillation. Chin Med J (Engl) 125: 2346-2348, 2012.

8. Tsung A, Sahai R, Tanaka H, Nakao A, Fink MP, Lotze MT, Yang H, Li J, Tracey KJ, Geller DA, et al: The nuclear factor HMGB1 mediates hepatic injury after murine liver ischemia-reperfusion. J Exp Med 201: 1135-1143, 2005.

9. Bartel DP: MicroRNAs: Genomics, biogenesis, mechanism, and function. Cell 116: 281-297, 2004.

10. Eulalio A, Huntzinger E and Izaurralde E: Getting to the root of miRNA-mediated gene silencing. Cell 132: 9-14, 2008.

11. Perron MP and Provost P: Protein interactions and complexes in human microRNA biogenesis and function. Front Biosci 13: 2537-2547, 2008

12. Hwang HW and Mendell JT: MicroRNAs in cell proliferation, cell death, and tumorigenesis. Br J Cancer 94: 776-780, 2006.

13. Ren XP, Wu J, Wang X, Sartor MA, Qian J, Jones K, Nicolaou P, Pritchard TJ and Fan GC: MicroRNA-320 is involved in the regulation of cardiac ischemia/reperfusion injury by targeting heat-shock protein 20. Circulation 119: 2357-2366, 2009.

14. Van Rooij E and Olson EN: MicroRNAs: Powerful new regulators of heart disease and provocative therapeutic targets. J Clin Invest 117: 2369-2376, 2007.

15. Cheng Y, Zhu P, Yang J, Liu X, Dong S, Wang X, Chun B, Zhuang $J$ and Zhang $C$ : Ischaemic preconditioning-regulated miR-21 protects heart against ischaemia/reperfusion injury via anti-apoptosis through its target PDCD4. Cardiovasc Res 87: 431-439, 2010. 
16. Tang Y, Zheng J, Sun Y, Wu Z, Liu Z and Huang G: MicroRNA-1 regulates cardiomyocyte apoptosis by targeting Bcl-2. Int Heart J 50: 377-387, 2009.

17. Ye Y, Hu Z, Lin Y, Zhang C and Perez-Polo JR: Downregulation of microRNA-29 by antisense inhibitors and a PPAR-gamma agonist protects against myocardial ischaemia-reperfusion injury. Cardiovasc Res 87: 535-544, 2010.

18. Zhang X, Wang X, Zhu H, Zhu C, Wang Y, Pu WT, Jegga AG and Fan GC: Synergistic effects of the GATA-4-mediated miR-144/451 cluster in protection against simulated ischemia/reperfusion-induced cardiomyocyte death. J Mol Cell Cardiol 49: 841-850, 2010.

19. Agarwal V, Bell GW, Nam JW, Bartel DP: Predicting effective microRNA target sites in mammalian mRNAs. Elife 4, 2015.

20. National Research Council (US) Committee for the Update of the Guide for the Care and Use of Laboratory Animals (eds) Guide for the Care and Use of Laboratory Animals. Nationa Academies Press (US), Washington (DC), 2011.

21. Hu X, Zhou X, He B, Xu C, Wu L, Cui B, Wen H, Lu Z and Jiang H: Minocycline protects against myocardial ischemia and reperfusion injury by inhibiting high mobility Group box 1 protein in rats. Eur J Pharmacol 638: 84-89, 2010.

22. Livak KJ and Schmittgen TD: Analysis of relative gene expression data using real-time quantitative PCR and the 2(-Delta Delta C(T)) Method. Methods 25: 402-408, 2001.

23. Xie J, Zhou X, Hu X and Jiang H: H2O2 evokes injury of cardiomyocytes through upregulating HMGB1. Hellenic J Cardiol 55: 101-106, 2014.

24. Bergamaschi A and Katzenellenbogen BS: Tamoxifen downregulation of miR-451 increases 14-3-3ל and promotes breast cancer cell survival and endocrine resistance. Oncogene 31: 39-47, 2012.

25. Lopotová T, Záčková M, Klamová $H$ and Moravcová J: MicroRNA-451 in chronic myeloid leukemia:miR-451-BCR-ABL regulatory loop? Leuk Res 35: 974-977, 2011.
26. Yu D, dos Santos CO, Zhao G, Jiang J, Amigo JD, Khandros E, Dore LC, Yao Y, D'Souza J, Zhang Z, et al: miR-451 protects against erythroid oxidant stress by repressing 14-3-3zeta. Genes Dev 24: 1620-1633, 2010.

27. Wang X, Zhu H, Zhang X, Liu Y, Chen J, Medvedovic M, Li H, Weiss MJ, Ren X and Fan GC: Loss of the miR-144/451 cluster impairs ischaemic preconditioning-mediated cardioprotection by targeting Rac-1. Cardiovasc Res 94: 379-390, 2012.

28. Tsung A, Klune JR, Zhang X, Jeyabalan G, Cao Z, Peng X, Stolz DB, Geller DA, Rosengart MR and Billiar TR: HMGB1 release induced by liver ischemia involves Toll-like receptor 4 dependent reactive oxygen species production and calcium-mediated signaling. J Exp Med 204: 2913-2923, 2007.

29. Yang QW, Xiang J, Zhou Y, Zhong Q and Li JC: Targeting HMGB1/TLR4 signaling as a novel approach to treatment of cerebral ischemia. Front Biosci (Schol Ed) 2: 1081-1091, 2010.

30. Yang Z, Deng Y, Su D, Tian J, Gao Y, He Z and Wang X: TLR4 as receptor for HMGB1-mediated acute lung injury after liver ischemia/reperfusion injury. Lab Invest 93: 792-800, 2013.

31. Andersson U, Wang H, Palmblad K, Aveberger AC, Bloom O, Erlandsson-Harris H, Janson A, Kokkola R, Zhang M, Yang H, et al: High mobility Group 1 protein (HMG-1) stimulates proinflammatory cytokine synthesis in human monocytes. J Exp Med 92: 565-570, 2000.

32. Sha Y, Zmijewski J, Xu Z and Abraham E: HMGB1 develops enhanced proinflammatory activity by binding to cytokines. J Immunol 180: 2531-2537, 2008.

33. Xu H, Yao Y, Su Z, Yang Y, Kao R, Martin CM and Rui T: Endogenous HMGB1 contributes to ischemia-reperfusion-induced myocardial apoptosis by potentiating the effect of TNF-\&alpha;/JNK. Am J Physiol Heart Circ Physiol 300: H913-921, 2011 